\title{
Comparing Transcatheter Aortic Valve Replacement (AVR) With Surgical AVR in Lower Risk Patients: A Comprehensive Meta-Analysis and Systematic Review
}

\author{
Muhammad Shayan Khan ${ }^{\mathrm{a}, \mathrm{g}}$, Tanveer Mirb, Waqas Ullah ${ }^{\mathrm{c}}$, Zain Alic, \\ Owais Idris ${ }^{\mathrm{d}}$, Ghazal Khan ${ }^{\mathrm{e}}$, Mamoon Ur Rashidf, Salman ${ }^{\mathrm{a}}$, \\ Mobasser Mehmood ${ }^{\mathrm{d}}$, Syed Sohail Ali ${ }^{\mathrm{d}}$
}

\begin{abstract}
Background: Transcutaneous aortic valve replacement (TAVR) is a novel percutaneous procedure for severe aortic stenosis and has been recently approved by Food and Drug Administration in lower risk patients. We performed the first ever meta-analysis and literature review of clinical trials comparing both 30-day and 1-year outcomes in lower risk patients undergoing TAVR vs. surgical aortic valve replacement (SAVR, having Society of Thoracic Surgeons score $<4 \%$ or equivalent).

Methods: Using predefined selection criteria as above, 68 articles were identified. Seven eligible articles were selected after extensive review. Primary effect outcomes were 30-day and 1-year all-cause mortality using risk ratio $(\mathrm{RR})$ with significant $\mathrm{P}$ value of $<0.05$.

Results: A total of 4,859 subjects were included. Risk of 30-day all-cause mortality was $40.1 \%$ less in TAVR group, RR $0.59(95 \%$ confidence interval $(\mathrm{CI}): 0.38-0.92, \mathrm{P}=0.02)$ with no significant heterogeneity. Six studies except Schymik et al also reported 1-year risk. This was, however, not statistically significant with a $21 \%$ decrease in the TAVR group, RR 0.79 (95\% CI: $0.57-1.09, \mathrm{P}=0.15)$. Six studies reported 30-day risk of secondary outcomes. The risk of 30 -day stroke was $36 \%$ less in TAVR group, although this was not statistically significant, RR 0.64 (95\% CI: $0.38-1.9, \mathrm{P}=0.10)$. The risk of acute kidney injury (AKI) stage 2 and above was $56 \%$ less in
\end{abstract}

Manuscript submitted February 29, 2020, accepted March 18, 2020

${ }^{a}$ Department of Internal Medicine, Mercy St Vincent Medical Center, Toledo, $\mathrm{OH} 43608$, USA

${ }^{b}$ Department of Internal Medicine, Detroit Medical Center, Wayne State University, Detroit, MI 48201, USA

'Department of Internal Medicine, Abington Jefferson Health, Abington, PA 19001, USA

${ }^{\mathrm{d}}$ Department of Cardiology, Mercy Saint Vincent Medical Center, Toledo, OH 43608, USA

'University of Missouri, Kansas City, MO 64110, USA

fDepartment of Internal Medicine, Advent Health, Orlando, FL 32803, USA

'Corresponding Author: Muhammad Shayan Khan, Department of Internal Medicine, Mercy Saint Vincent Medical Center, Toledo, OH 43608, USA.

Email: muhammadshayankhan1@gmail.com

doi: https://doi.org/10.14740/cr1046
post-TAVR patients, RR 0.43 (95\% CI: $0.35-0.54, \mathrm{P}<0.001)$ with no heterogeneity. For vascular complications, RR was high in TAVR group $4.62(95 \% \mathrm{CI}: 1.42-15.18, \mathrm{P}=0.01)$. Significant heterogeneity was demonstrated though $\left(\mathrm{I}^{2}=81\right)$. The risks for permanent pacemaker (PPM) were also higher in the TAVR group, RR 3.30 (95\% CI: $2.04-5.33, \mathrm{P}<0.001)$ and significant heterogeneity was observed. After removing Thyregod et al and Partner 3 trial from the analysis, heterogeneity was removed, but the RR was still high 3.21 (95\% CI: $2.54-4.068, \mathrm{P}<0.001$ ). Post-operative incidence of endocarditis among TAVR patients was low but not statistically significant. The 30-day risk for infective endocarditis was RR 0.67 (95\% CI: 0.13 $3.48, \mathrm{P}=0.63)$. The 1 -year risk was similarly low but not significant, RR 0.73 (95\% CI: $0.28-1.92, \mathrm{P}=0.53)$.

Conclusions: Among low risk patients, TAVR was found to be superior in short-term all-cause mortality and 1-year stroke, a result that was statistically significant for TAVR and close to significance for stroke. TAVR patients were also less likely to have post-operative bleeding and AKI stage 2 and beyond. Post-operative incidence of endocarditis among TAVR patients was low but not statistically significant. However, the rates of PPM and vascular complications are higher in TAVR patients. The results of TAVR in low risk population are thus extremely encouraging. However, the issue of long-term valve durability in this group needs further studies. Also, caution needs to be exercised while extending the indications to extremely young patients due to lack of enough studies.

Keywords: Transcatheter aortic valve replacement; Surgical aortic valve replacement; Low risk; All-cause mortality; Stroke

\section{Introduction}

Transcutaneous aortic valve replacement (TAVR) is a novel percutaneous procedure for aortic stenosis. It was initially approved by the Food and Drug Administration (FDA) in patients at high and intermediate risk for surgery due to comparable mortality outcomes [1]. Recently, several compelling trials such as Partner 3 trial and Evolut Low Risk trials allowed the FDA to approve TAVR not only for high and intermediate risk but also for low surgical risk patients [2-4]. 
TAVR in low surgical risk patients is, although still debatable. A 2016 meta-analysis by Arora et al compared four previous trials in low risk patients as stratified by low Society of Thoracic Surgeons Predicted Risk of Mortality (STS-PROM) or Euro mean scores and showed better results in TAVR patients regarding 30-day mortality and secondary outcomes, although the data were not statistically significant $[5,6]$. Patients with TAVR were also noted to have higher vascular complications with an increased risk of post-procedure permanent pacemaker (PPM) implantation. However, now with the addition of three major trials over the last 3 years, we attempt to compare these trials once again in regards to both short- and long-term morbidity and mortality. Hopefully, with the addition of more power and the first time ever study of long-term complications, this will be helpful in providing new insights as what to expect in low risk patients in the future.

\section{Objectives}

We attempt hereby to perform a meta-analysis and literature review of clinical trials involving human intervention studies comparing both short-term (30 day) and long-term (1 year) complications of TAVR vs. SAVR in low risk patients. Our hypothesis was that TAVR is superior both in morbidity and mortality to SAVR in patients at lower surgical risks. This is the first ever meta-analysis comparing both long- and short-term complications involving the most number of studies published yet.

\section{Materials and Methods}

We followed the preferred reporting items for systematic reviews and meta-analyses (PRISMA) guidelines [7].

\section{Search strategy}

A predefined inclusion criterion was established in advance. Potentially relevant published clinical trials were identified in Medline, Embase, chemical abstracts and Biosis (from start of the databases till date). The following search items were used to search titles and abstracts: percutaneous? or transcatheter? or transcatheter aortic valve replacement? or TAVR? or TAVI and surgical aortic valve replacement in low risk patients or SAVR in low risk patients. Studies were considered low risk if the overall surgical risk was less than STSPROM score of $4 \%$, less than $5 \%$ and $10 \%$ for logistic Euro score I or logistic Euro score II, respectively. Studies were limited to involving humans only.

\section{Selection criteria}

Two researchers independently performed an electronic search of PubMed and Web of Science databases. The study was limited to human intervention studies involving TAVR vs. SAVR with Society of Thoracic Surgeons score (STSS) definition of low risk patients with a score less than $4 \%$ or equivalent mean European System for Cardiac Operative Risk Evaluation (Euro SCORE) [8-12]. Observational studies were excluded to determine better cause and effect analysis. No language restrictions were made. Studies were included if they met the following criteria: intervention with TAVR or SAVR as the only or a part of the variables and primary outcome of interest as 30-day and 1-year mortality. Secondary outcomes included 30day and 1-year risk of stroke, pacemaker implantation, major vascular complications, valvular endocarditis, new onset atrial fibrillation and acute kidney injury (AKI) stage 2 and above. Sixty-eight articles were identified after the search. The second selection step involved proof-reading of those articles to ensure the first step was performed correctly. Articles were excluded if data on SAVR or TAVR were missing or primary and secondary outcomes of interest were not available. In case of unclarity, inclusion of the studies was discussed amongst the authors to arrive at a final decision.

\section{Data extraction and statistical analysis}

Data were extracted from each study using a standardized spread sheet which involved study identification (author, year of publication and country), study type, percent males, type of valve used, subject baseline characteristics with history of coronary artery disease, peripheral arterial disease, myocardial infarction, chronic lung disease, peripheral neuropathy, number of cases in surgical and transcatheter arms, intravenous (IV) access route used whether femoral or radial, time of exposure, 30-day mortality, 30-day and 1-year stroke, 30-day new onset atrial fibrillation and miscellaneous notes at the end.

As a primary effect estimate, risk ratio (RR) and 95\% confidence interval (CI) across studies were used with significant $\mathrm{P}$ valve $<0.05$. Comprehensive meta-analysis and Cochrane Review Manager was used to calculate the primary effect size and $95 \% \mathrm{CI}$. In order to determine the pooled overall effect, we weighed the studies by inverse of their variance $\left(1 / \mathrm{SE}^{2}\right)$ (SE: standard error), as in Figure 1. Thus, more weightage was given to more precise studies. If significant heterogeneity was found, sensitivity analysis was conducted and studies having significant heterogeneity were discarded.

\section{Results}

The search through PubMed and Web of Science databases yielded 68 potentially relevant articles. Based on predefined exclusion criteria, 61 papers were excluded for various reasons. Seven randomized control trials [2-4, 12-15] were retrieved after the search. Seven studies from different countries including United States (USA), Italy, Germany, Finland, Denmark and Sweden were included in the meta-analysis. A total of 4,859 subjects were included. The number of subjects ranged from 254 in the SURTAVI trial [15] to 1,403 in Evolut Low Risk trial [4]. Mean age ranged from 73 years in Partner 3 trial [3] to 83.7 years in Fraccaro et al [2]. Reported compliance was $100 \%$ (Table 1$)$. 


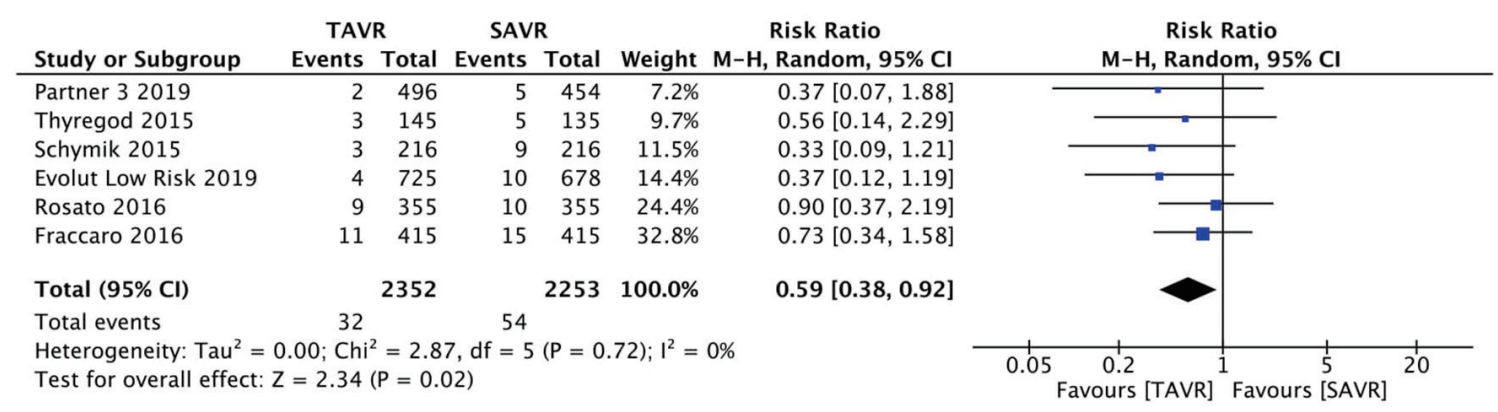

Figure 1. Random effect meta-analysis and forest plot of 30-day risk of mortality among patients undergoing TAVR, as compared to SAVR. TAVR: transcutaneous aortic valve replacement; SAVR: surgical aortic valve replacement.

\section{Primary effect outcome}

Six out of seven studies reported 30-day mortality. The 30day risk of all-cause mortality was $0.4 \%$ to $2.7 \%$ for TAVR patients as compared to $1.1 \%$ to $4.2 \%$ amongst SAVR patients. Overall, there was a $40.1 \%$ statistically significant decrease in risk of 30-day overall mortality for TAVR vs. SAVR patients, RR 0.59 (95\% CI: $0.38-0.92, \mathrm{P}=0.02$ ) (Fig. 1). This is a new finding in contrast to previous meta-analysis by Arora et al [5], which did not find any statistically significant difference between 30-day all-cause mortality in TAVR and SAVR. No significant heterogeneity was observed, $\mathrm{I}^{2}=0 \%$. Forest plot and relative weights of each study are demonstrated in Figure 1. In order to assess for publication bias, a funnel plot of each study was constructed against their respective precisions (Fig.
2). Absence of publication bias is reflected in an intercept close to zero with the slope of regression line close to overall effect size. Although the small number of studies limited its interpretation, a subjective impression of funnel plot demonstrated some asymmetry to the right of the mean effect.

Six out of seven studies except Schmyick et al [13] reported 1-year all-cause mortality too. There was also a $21 \%$ decrease in the TAVR group, RR 0.79 (95\% CI: $0.57-1.09, \mathrm{P}$ $=0.15$ ) (Fig. 3). However, it was not statistically significant.

\section{Secondary effect outcome}

Six out of seven studies reported 30-day risk of secondary outcomes. The 30 -day risk of stroke was $0.6 \%$ to $3.4 \%$ for

Table 1. Baseline Characteristics of All Studies

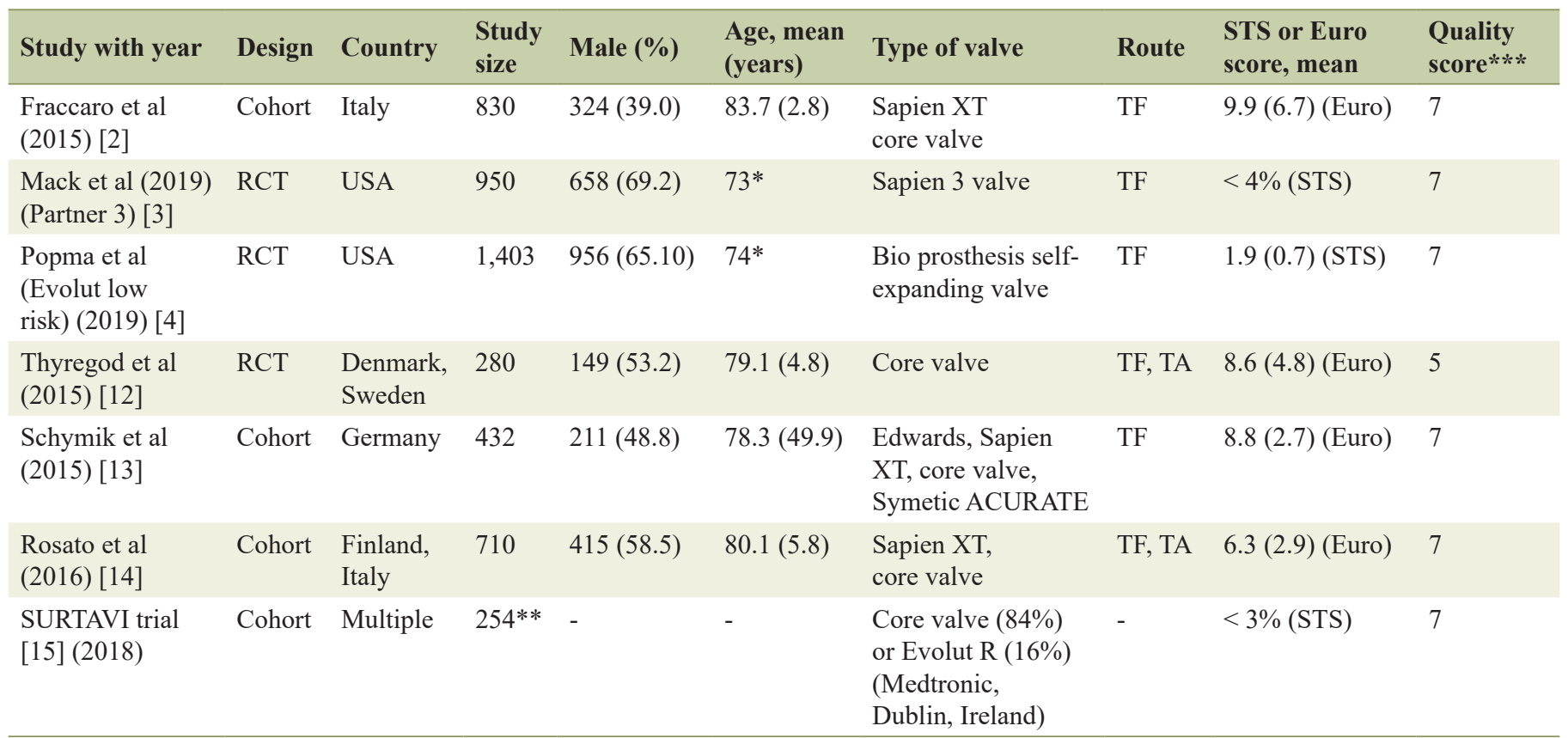

${ }^{*}$ Age separately reported in both groups. ${ }^{* *}$ Included in current meta-analysis. ${ }^{* *}$ Criteria used for scoring: proper randomization (score: 1 point), similarity of treatment groups in relevant variables at baseline (1 point), blinding of subjects and investigators (1 point for each), specified eligibility criteria (1 point), valid point estimates and measures of variability (1 point) and data on degree of compliance (1 point). TF: transfemoral; TA: transapical; STS: Society of Thoracic Surgeons score; RCT: randomized controlled trial. 


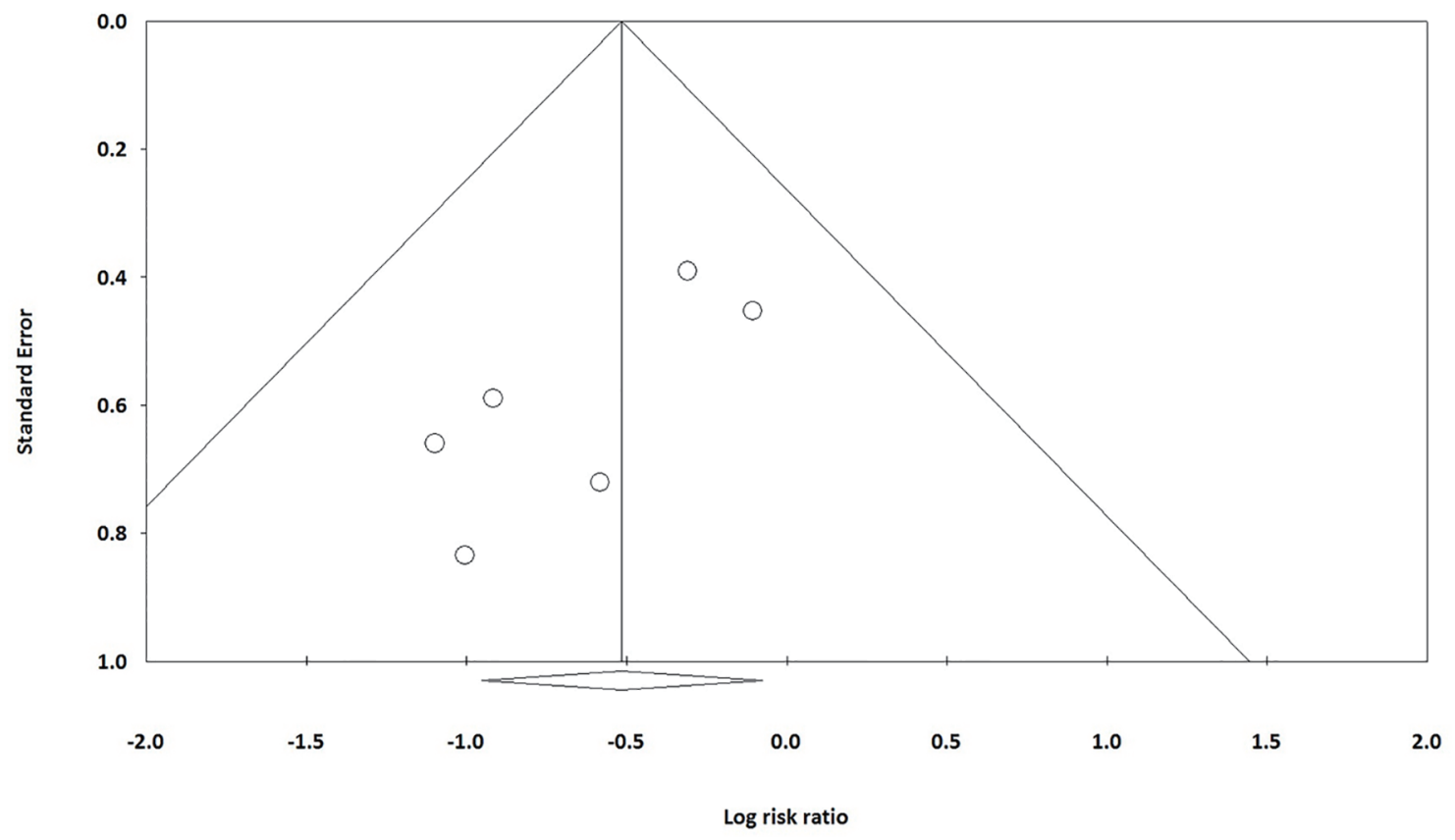

Figure 2. Publication bias of included studies in regards to 30-day mortality. X-axis: log risk ratio. Y-axis: standard error of the mean.

TAVR patients as compared to $0.9 \%$ to $3.4 \%$ amongst SAVR patients. Patients having TAVR were $36 \%$ less likely to have stroke as compared to SAVR patients although this was not statistically significant, RR $0.64(95 \%$ CI: $0.38-1.1)$. This is in concordance with previously reported by Arora et al. No significant heterogeneity was observed, $\mathrm{I}^{2}=23 \%, \mathrm{P}=0.10$ (Fig. 4). A funnel plot of log of risk ratio against standard error of the mean demonstrated no significant publication bias (Fig. 5).

Regarding long-term risk of stroke, four studies including SURTAVI trial, Thyregod et al, Partner 3 trial and Evolut Low Risk trial reported 1-year incidence, while Rosato et al mentioned 3 years at follow-up. The incidence of stroke in the 1-year follow-up group was 31\% less in TAVR patients, RR 0.69 (95\% CI: $0.47-1.00, \mathrm{P}=0.05)$ (Fig. 6). This is a novel finding in contrast to any previous meta-analysis and the P-value was almost close to significance here. This also underlies the importance of greater power in studies. Hopefully with more trials in the future, we can have a better un- derstanding of whether TAVR is actually beneficial to stroke. No significant heterogeneity was observed, $\mathrm{I}^{2}=0 \%$.

Mentioning other secondary outcomes, the risk of AKI stage 2 and above was $56 \%$ less in post-TAVR patients at 30 days, RR 0.43 (95\% CI: $0.35-0.54, \mathrm{P}<0.001)$ (Fig. 7). No heterogeneity was observed, $\mathrm{I}^{2}=0.0 \%$.

Regarding PPM implantation and vascular complications, the risk was inherently high for TAVR patients for both (Figs. 8 and 9). The risks for PPM implantation were higher in the TAVR group at 30 days, RR 3.30 (95\% CI: $2.04-5.33, \mathrm{P}<$ $0.001)$. Significant heterogeneity was also observed in this group: $\mathrm{I}^{2}=75 \%, \mathrm{P}=0.001$. After removing Thyregod et al and Partner 3 trial from the analysis, heterogeneity was removed, but the RR was still high, RR 3.21 (95\% CI: $2.54-4.068, \mathrm{P}<$ $0.001)$.

Regarding vascular complications, RR was 4.62 (95\% CI: $1.42-15.18, \mathrm{P}=0.01)$. Significant heterogeneity was demonstrated though, $\mathrm{I}^{2}=81 \%$.

Post-operative valvular endocarditis was reported by four

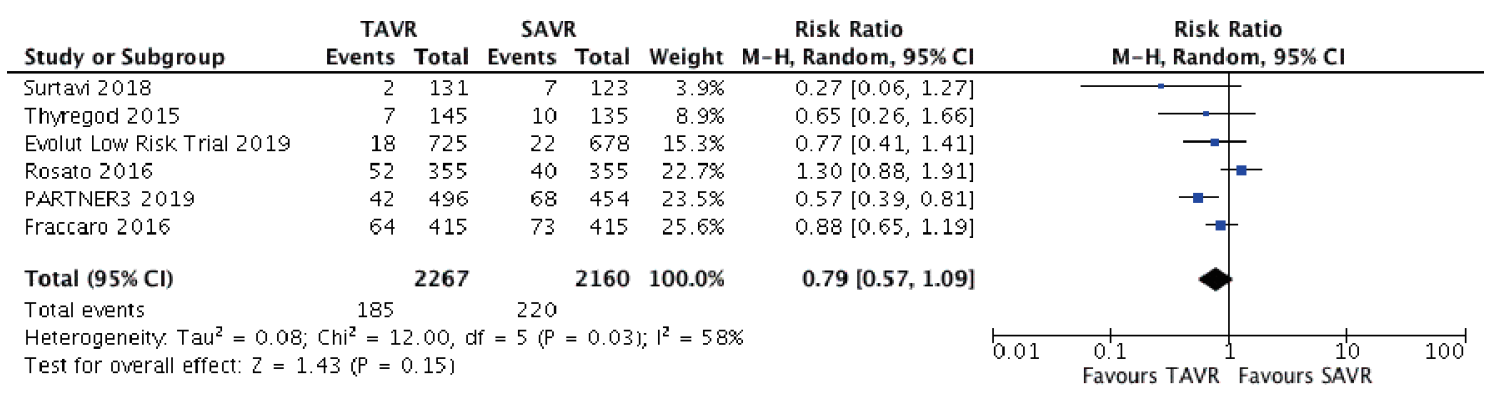

Figure 3. Random effect meta-analysis and forest plot of 1-year risk of mortality among patients undergoing TAVR, as compared to SAVR. TAVR: transcutaneous aortic valve replacement; SAVR: surgical aortic valve replacement. 


\begin{tabular}{|c|c|c|c|c|c|c|c|c|c|c|}
\hline Study or Subgroup & \multicolumn{2}{|c|}{ TAVR } & \multicolumn{2}{|c|}{ SAVR } & Weight & $\begin{array}{c}\text { Risk Ratio } \\
\text { M-H, Random, } 95 \% \mathrm{Cl}\end{array}$ & \multicolumn{4}{|c|}{$\begin{array}{c}\text { Risk Ratio } \\
\text { M-H, Random, } 95 \% \mathrm{Cl}\end{array}$} \\
\hline Thyregod 2015 & 2 & 145 & 4 & 135 & $8.7 \%$ & $0.47[0.09,2.50]$ & & & & \\
\hline Rosato 2016 & 4 & 355 & 4 & 355 & $12.2 \%$ & $1.00[0.25,3.97]$ & & & & \\
\hline Schymik 2015 & 3 & 216 & 2 & 216 & $7.9 \%$ & $1.50[0.25,8.89]$ & & & & \\
\hline Fraccaro 2016 & 4 & 415 & 12 & 415 & $16.9 \%$ & $0.33[0.11,1.03]$ & & & & \\
\hline Partner 32019 & 3 & 496 & 11 & 454 & $14.0 \%$ & $0.25[0.07,0.89]$ & & & & \\
\hline Evolut Low Risk 2019 & 25 & 725 & 25 & 678 & $40.3 \%$ & $0.94[0.54,1.61]$ & & & & \\
\hline Total $(95 \% \mathrm{Cl})$ & & 2352 & & 2253 & $100.0 \%$ & $0.64[0.38,1.09]$ & & & & \\
\hline Total events & 41 & & 58 & & & & & & & \\
\hline $\begin{array}{l}\text { Heterogeneity: } \mathrm{Tau}^{2}= \\
\text { Test for overall effect: }\end{array}$ & $\begin{array}{l}.10 ; \mathrm{Chi}^{2} \\
=1.63\end{array}$ & $\begin{array}{l}2=6.5 \\
(P=0.1\end{array}$ & $\begin{array}{l}3, \mathrm{df}=5 \\
10)\end{array}$ & $(P=0$. & $26) ; 1^{2}=$ & $23 \%$ & $\frac{1}{0.002}$ & $\begin{array}{cc}1 & 1 \\
0.1 & 1\end{array}$ & $\begin{array}{c}10 \\
\text { Favours [S }\end{array}$ & $\frac{1}{500}$ \\
\hline
\end{tabular}

Figure 4. Random effect meta-analysis and forest plot of 30-day risk of stroke among patients undergoing TAVR, as compared to SAVR. TAVR: transcutaneous aortic valve replacement; SAVR: surgical aortic valve replacement.

studies. Regarding 30-day and 1-year results, the risk was lower for TAVR patients for both (Figs. 10 and 11). However, results were not statistically significant due to low power of the study. The 30-day risk for infective endocarditis was RR 0.67 (95\% CI: $0.13-3.48, \mathrm{P}=0.63$ ). The 1 -year risk was similarly low but not significant, RR 0.73 (95\% CI: $0.28-1.92, \mathrm{P}=0.53)$ (Table 2).

\section{Quality assessment}

Quality across included studies was measured by subjective analysis of risk of multiple biases presented as percentages. Except for Thyregod et al which was a non-blinded study where the risk of performance bias and detection bias was high, other biases were low across almost every study as shown in Figures 12 and 13.

We also assessed quality using a scoring system based on the Delphi consensus for meta-analysis [16]. The following criteria were used for scoring: proper randomization (score: 1 point), similarity of treatment groups in relevant variables at baseline ( 1 point), blinding of subjects and investigators (1 point for each), specified eligibility criteria (1 point), valid point estimates and measures of variability ( 1 point) and data on degree of compliance (1 point). Thus, a combined score was calculated for each study which could range from 0 to 7 points. Almost every study had a high quality score based on this scoring, except Thyregod et al which had a score of 5. Quality scores for each study are illustrated in Table 1 [2-4, 12-15].

\section{Funnel Plot of Standard Error by Log risk ratio}

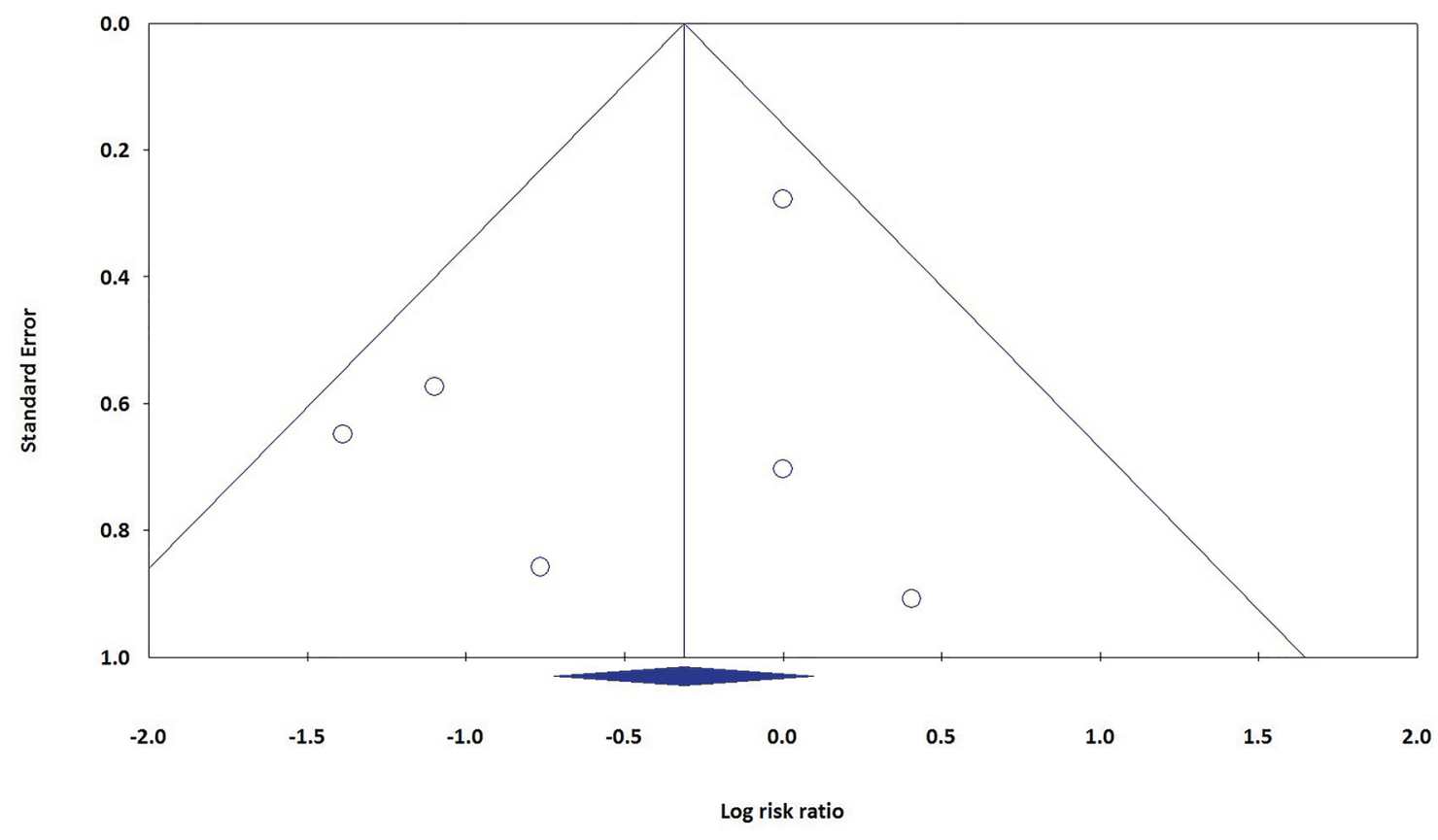

Figure 5. Publication bias of included studies in regards to 30-day incidence of stroke. X-axis: log risk ratio. Y-axis: standard error of the mean. 


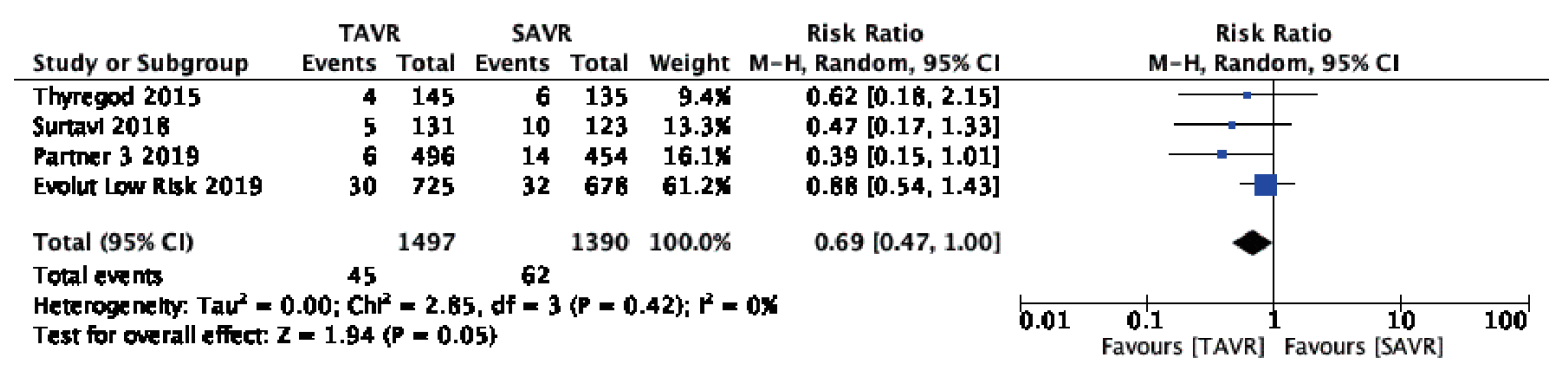

Figure 6. Random effect meta-analysis and forest plot of 1-year risk of stroke among patients undergoing TAVR, as compared to SAVR. TAVR: transcutaneous aortic valve replacement; SAVR: surgical aortic valve replacement.

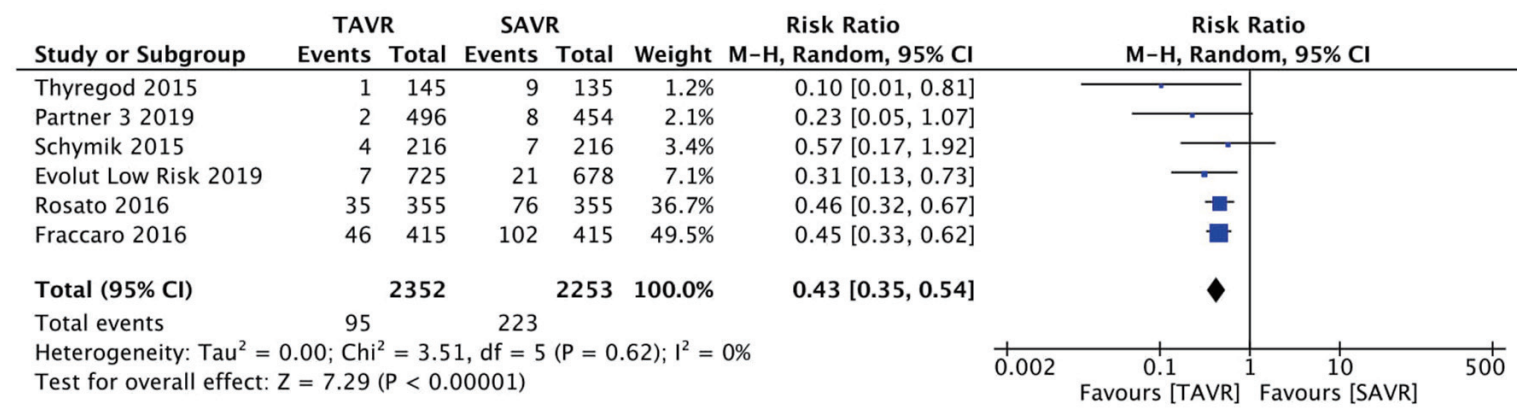

Figure 7. Random effect meta-analysis and forest plot of 30-day risk of acute kidney injury stage 2 and above among patients undergoing TAVR, as compared to SAVR. TAVR: transcutaneous aortic valve replacement; SAVR: surgical aortic valve replacement.

\begin{tabular}{|c|c|c|c|c|c|c|c|c|c|c|}
\hline Study or Subgroup & \multicolumn{2}{|c|}{ TAVR } & $\begin{array}{r}\text { SAV } \\
\text { Events }\end{array}$ & $\begin{array}{l}\mathbf{R} \\
\text { Total } \\
\end{array}$ & Weight & Risk Ratio & \multicolumn{4}{|c|}{$\begin{array}{c}\text { Risk Ratio } \\
\text { M-H, Random, } 95 \% \mathrm{Cl}\end{array}$} \\
\hline Thyregod 2015 & 46 & 145 & 2 & 135 & $8.0 \%$ & $21.41[5.30,86.51]$ & & & $=$ & \\
\hline Rosato 2016 & 44 & 355 & 9 & 355 & $16.0 \%$ & $4.89[2.42,9.86]$ & & & $\longrightarrow$ & \\
\hline Schymik 2015 & 30 & 216 & 10 & 216 & $16.2 \%$ & $3.00[1.50,5.98]$ & & & $\varpi$ & \\
\hline Fraccaro 2016 & 54 & 415 & 15 & 415 & $18.4 \%$ & $3.60[2.07,6.27]$ & & & $\neg$ & \\
\hline Partner 32019 & 36 & 496 & 24 & 454 & $19.3 \%$ & $1.37[0.83,2.26]$ & & & - & \\
\hline Evolut Low Risk 2019 & 142 & 725 & 49 & 678 & $22.2 \%$ & $2.71[1.99,3.69]$ & & & 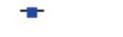 & \\
\hline Total $(95 \% \mathrm{Cl})$ & & 2352 & & 2253 & $100.0 \%$ & $3.30[2.04,5.33]$ & & & & \\
\hline Total events & 352 & & 109 & & & & & & & \\
\hline $\begin{array}{l}\text { Heterogeneity: } \mathrm{Tau}^{2}= \\
\text { Test for overall effect: }\end{array}$ & $\begin{array}{l}.25 ; \mathrm{Chi}^{2} \\
=4.87\end{array}$ & $\begin{array}{l}2=20 . \\
(P<0 .\end{array}$ & $\begin{array}{l}04, \mathrm{df}= \\
00001)\end{array}$ & $5(P=$ & $0.001) ; 1^{2}$ & $=75 \%$ & 0.002 & $\begin{array}{c}0.1 \\
\text { Favours [TAVR] }\end{array}$ & $\begin{array}{c}10 \\
\text { Favours [S }\end{array}$ & 500 \\
\hline
\end{tabular}

Figure 8. Random effect meta-analysis and forest plot of 30-day risk of permanent pacemaker implantation among patients undergoing TAVR, as compared to SAVR. TAVR: transcutaneous aortic valve replacement; SAVR: surgical aortic valve replacement.

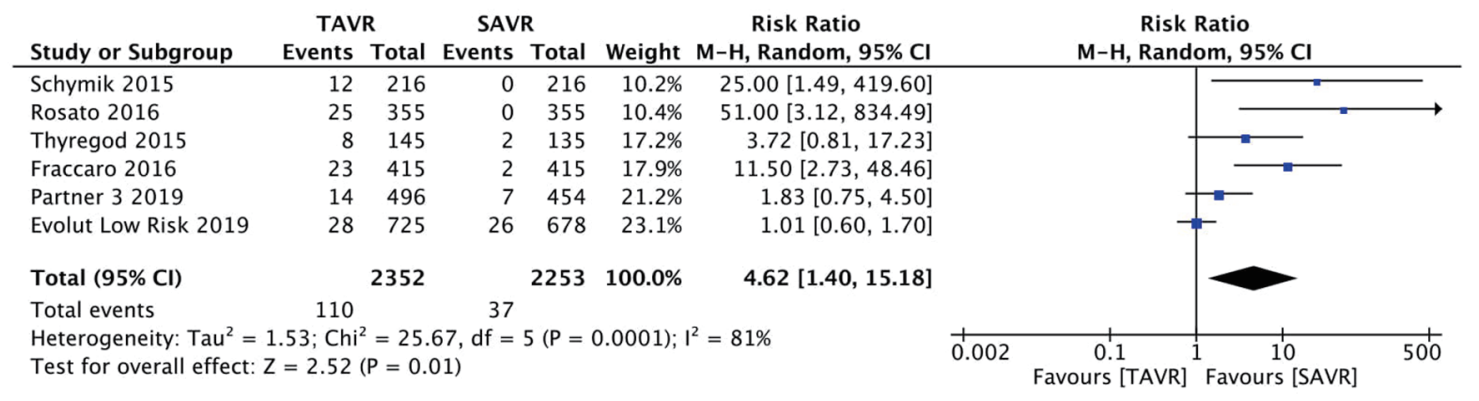

Figure 9. Random effect meta-analysis and forest plot of 30-day risk of major vascular complications among patients undergoing TAVR, as compared to SAVR. TAVR: transcutaneous aortic valve replacement; SAVR: surgical aortic valve replacement. 


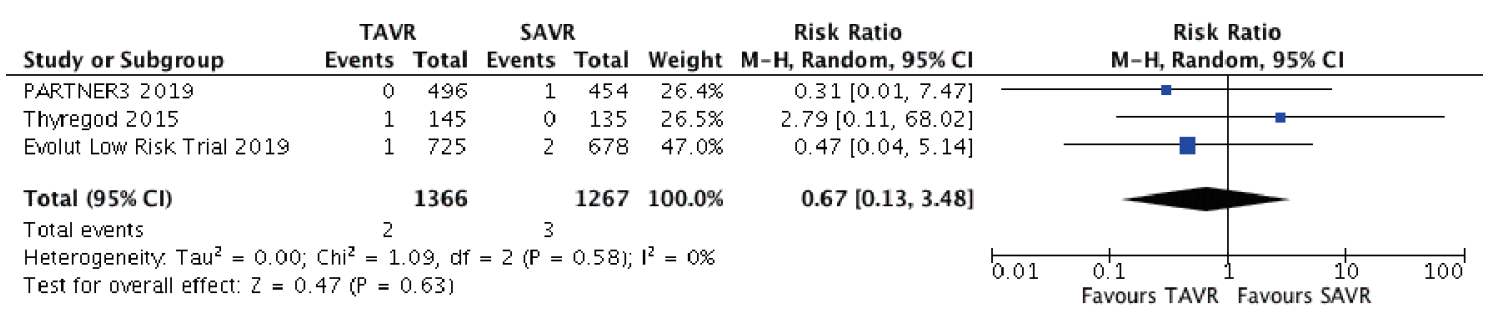

Figure 10. Random effect meta-analysis and forest plot of 30-day risk of infective endocarditis among patients undergoing TAVR, as compared to SAVR. TAVR: transcutaneous aortic valve replacement; SAVR: surgical aortic valve replacement.

\begin{tabular}{|c|c|c|c|c|c|c|c|c|c|c|}
\hline \multirow[b]{2}{*}{ Study or Subgroup } & \multicolumn{2}{|c|}{ TAVR } & \multicolumn{2}{|c|}{ SAVR } & \multirow[b]{2}{*}{ Weight } & \multirow{2}{*}{$\begin{array}{c}\text { Odds Ratio } \\
\text { M-H, Fixed, } 95 \% \mathrm{Cl}\end{array}$} & \multirow{2}{*}{\multicolumn{4}{|c|}{$\begin{array}{c}\text { Odds Ratio } \\
\text { M-H, Fixed, } 95 \% \mathrm{Cl}\end{array}$}} \\
\hline & Events & Total & Events & Total & & & & & & \\
\hline Surtavi 2018 & 0 & 131 & 1 & 123 & $15.8 \%$ & $0.31[0.01,7.69]$ & & & & \\
\hline Thyregod 2015 & 4 & 145 & 2 & 135 & $20.6 \%$ & $1.89[0.34,10.47]$ & & & $\longrightarrow$ & \\
\hline PARTNER3 2019 & 1 & 496 & 2 & 454 & $21.4 \%$ & $0.46[0.04,5.05]$ & & & & \\
\hline Evolut Low Risk Trial 2019 & 2 & 725 & 4 & 678 & $42.2 \%$ & $0.47[0.09,2.55]$ & & & & \\
\hline Total $(95 \% \mathrm{CI})$ & & 1497 & & 1390 & $100.0 \%$ & $0.73[0.28,1.92]$ & & & & \\
\hline Tatal events & 7 & & 9 & & & & & & & \\
\hline $\begin{array}{l}\text { Heterogeneity: } \mathrm{Chi}^{2}=1.87 \\
\text { Test for overall effect: } z=\end{array}$ & $\begin{array}{l}d f=3(\mathrm{P} \\
63 \mathrm{P}=\end{array}$ & $\begin{array}{l}=0.6 \\
0.531\end{array}$ & $\mathrm{j} ; \mathrm{I}^{2}=0$ & & & & 0.01 & $\begin{array}{c}\text { 'l.1 } \\
\text { Favours TAVR }\end{array}$ & 1 Favours S & $\begin{array}{l}10 \\
\text { SAVR }\end{array}$ \\
\hline
\end{tabular}

Figure 11. Random effect meta-analysis and forest plot of 30-day risk of infective endocarditis among patients undergoing TAVR, as compared to SAVR. TAVR: transcutaneous aortic valve replacement; SAVR: surgical aortic valve replacement.

\section{Discussion}

Our meta-analysis comprised of seven studies for a total of 4,859 patients, 2,483 in the TAVR group and 2,376 in the SAVR group. We found that TAVR patients have a decreased risk of 30-day mortality. This effect was statistically significant and the first time it has been demonstrated in low risk patients. This was also shown by two new clinical trials published this year, the Evolut low Risk [4] and the Partner 3 trial [3] which were a part of our meta-analysis. TAVR patients were also less likely to have stroke at 1 year, although the power of the study was low. TAVR patients were also less likely to have post-operative bleeding and AKI stage 2 and beyond, although they were significantly more prone to vascular complications and the need for PPM. All these effects were statistically significant and have been illustrated in Figures 1-11.

The results of previous trials led to the recognition of TAVR as the procedure of choice in inoperable patients and alternative to SAVR in intermediate to high risk, and recent trials have led the FDA to approve it for low risk patients too [17-20]. Effects of secondary outcomes have been the same in intermediate and high-risk patients with a higher chance of vascular complications and PPM need for both short and long term and a protective effect for TAVR patients in valvular endocarditis, AKI stage 2 and above [18-21]. The risk of AKI stage 1 has also been demonstrated to be low in multiple studies, as shown by the Partner 3 trial. The previous meta-analysis by Arora et al showed similar results, however, with significant heterogeneity. This was not seen in our study though, due to greater power.

The rate of post-procedure PPM in TAVR is high as reported by multiple previous studies and is troubling. Multiple theories have been proposed to explain this complication $[14,21,22]$. A study by Hamdan et al concluded that a short membranous septum (MS), insufficient difference between MS length and implantation depth, with other factors such as the presence of calcification factors that may all facilitate mechanical compression of the conduction tissue by the implanted valve, are good predictors of PPM implantation after TAVR

Table 2. Prevalence of Comorbidities Across Studies

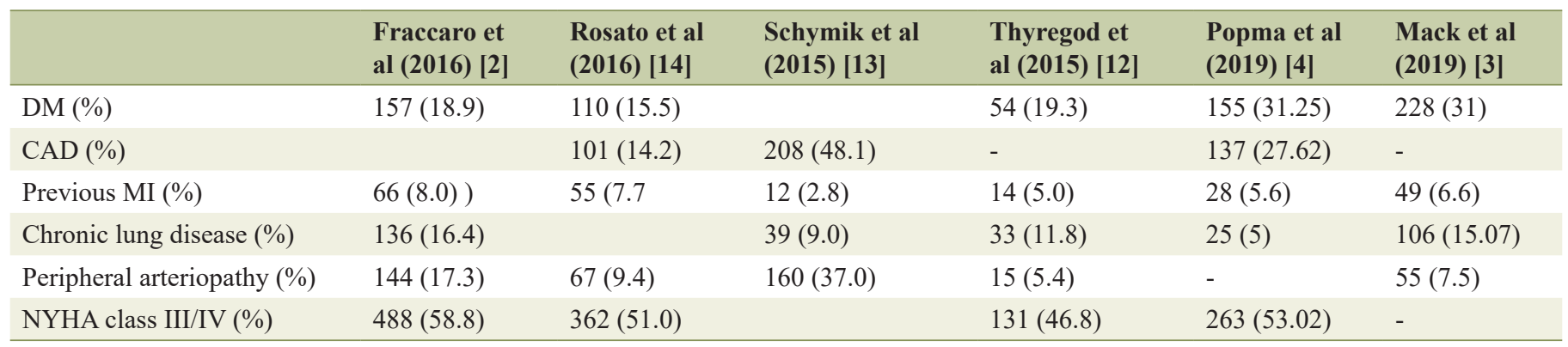

DM: diabetes mellitus; CAD: coronary artery disease; MI: myocardial infarction; NYHA: New York Heart Association. 


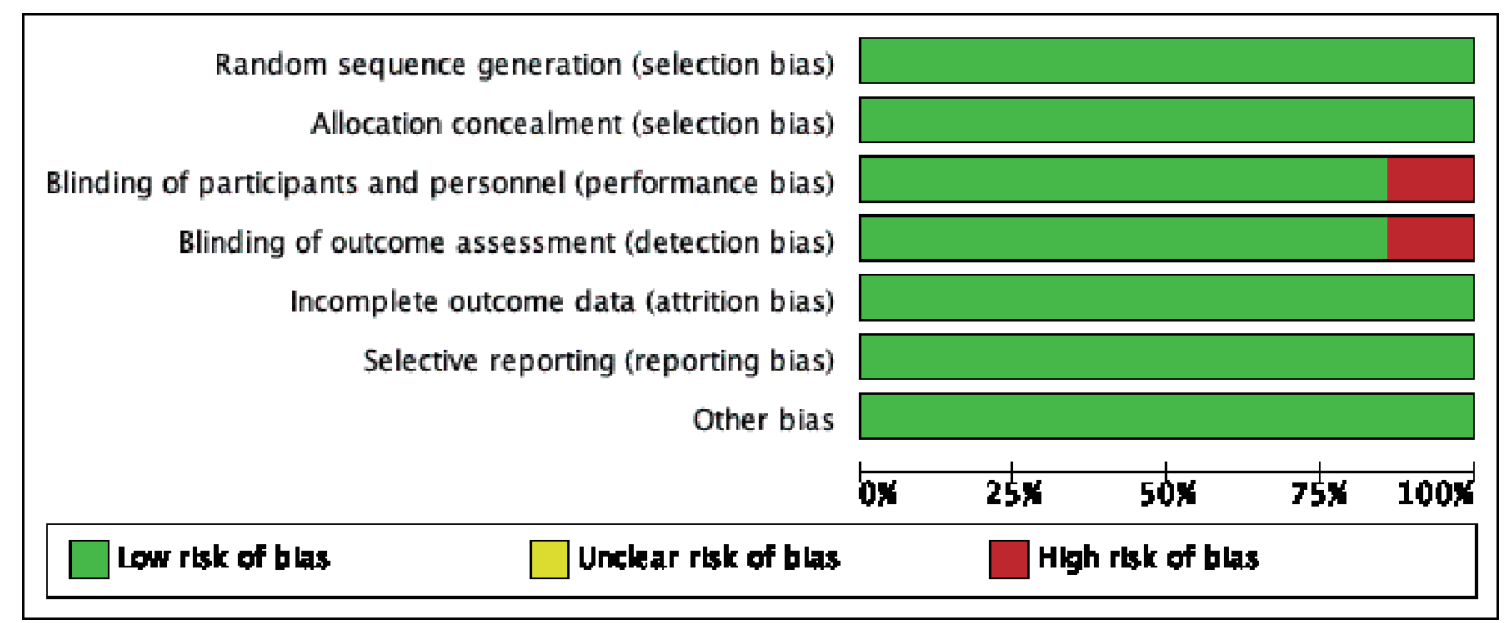

Figure 12. Risk of bias graph: review authors' judgments about each risk of bias item presented as percentages across all studies combined. All seven studies with 4,869 subjects were included. Green circle indicates a low risk of bias $<25 \%$. Red circle indicates a high risk of bias $>75 \%$. Risk of major biases low for all studies except for Thyregod et al, in which the risk of performance and detection bias was high.

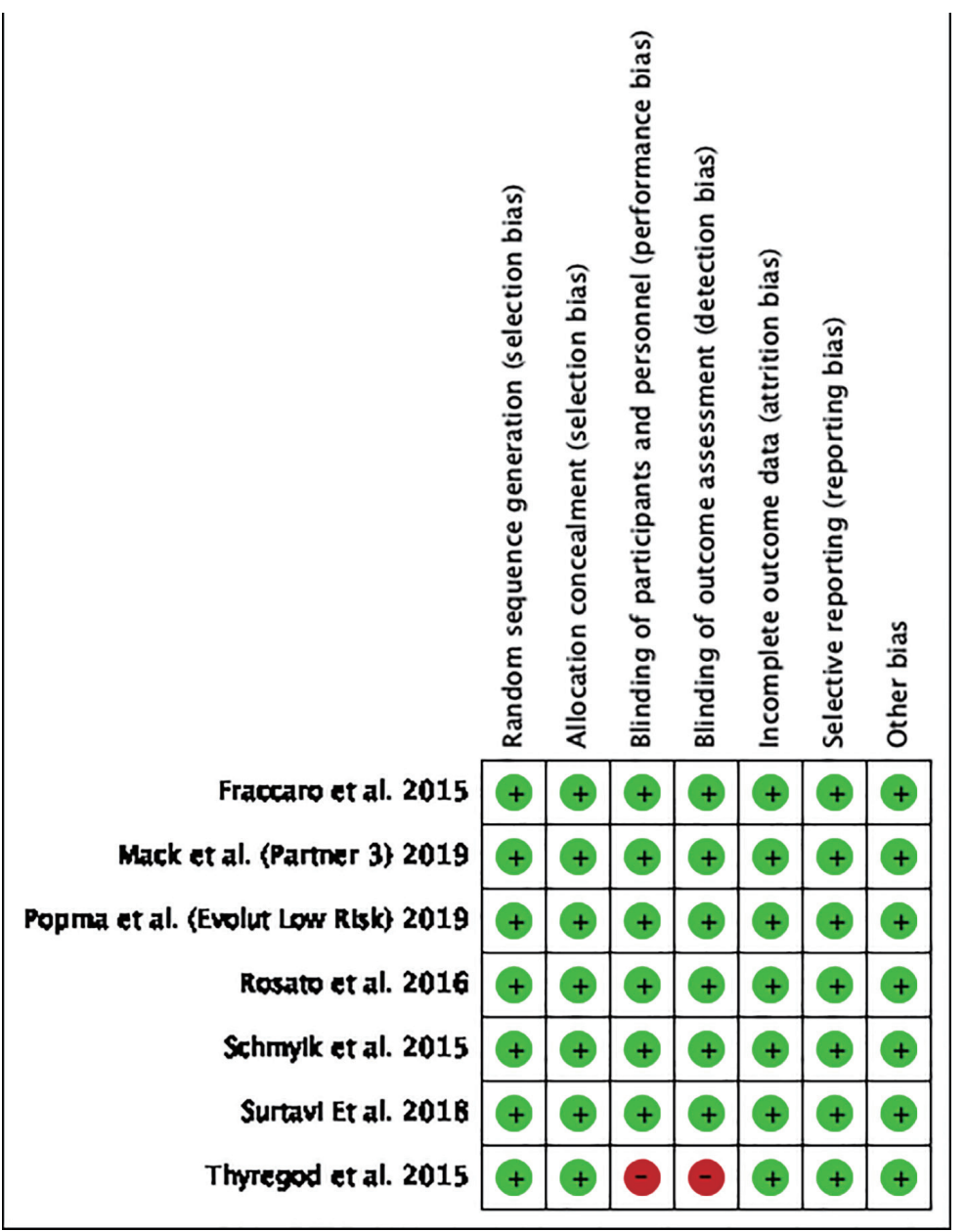

Figure 13. Risk of bias summary: review authors' judgments about each risk of bias item for each included study. Green circle indicates low risk of bias $<25 \%$. Red circle indicates high risk of bias $>75 \%$. Seven studies with 4,869 subjects were included. As shown above, risk of major biases low for all studies except for Thyregod et al, in which the risk of performance and detection bias was high. 
[21]. In fact, the single most important independent factor of post-procedural PPM implantation may be the length of MS and degree of calcification [21]. These variables may be assessed in determining whether to undergo an open procedure or transcatheter approach in low risk patients with no other contraindications; however, data are limited as of yet. The results with both SAPIEN 3 balloon expanding valve and Evolut self-expanding valve seem to be similar in Partner 3 and Evolut Low Risk trial with a higher risk of PPM in both. Partner 3 trial also showed beneficial results with surgery in comparing other secondary end points such as left branch block and paravalvular regurgitation.

Other rare complications such as rates of bio-prosthetic valve thrombosis, endocarditis and re-intervention are low and comparable in both TAVR and SAVR [4]. TAVR patients have also been shown to have lower aortic valve gradients and larger areas, specifically shown by the self-expanding valves used in Evolut Low Risk trial which is probably due to the supra-annular design of the prosthesis [23, 24].

\section{Strength and limitations}

The strengths of this meta-analysis include a comprehensive search of relevant studies by two different researchers, independent extraction of data to assess eligibility and reduce bias and selection of a relatively large subgroup of patients not assessed before.

Our study had several limitations. We included only randomized control trials which are although the gold standard for evaluating efficacy and safety but might miss some confounding factors usually noted by observational studies. Other limitations include comparison of different valves which may influence outcome of TAVR such as PPM or valvular insufficiency. We also failed to stratify patients into different subgroups according to different access of intervention. A previous study showed a superiority of trans-femoral access in comparison to trans-apical access; however, that study was conducted in both low and intermediate risk patients [25].

Significant heterogeneity was observed in some effect outcomes; however, we used sensitivity analysis to analyze which study was causing the effect and recalculated data after dropping the study. Also, as with all meta-analysis, the quality of the study is as good as the quality of the trials itself. However, almost all studies used in this analysis were propensity-score matched which reduced the risk of bias.

\section{Conclusions}

In conclusion, among low risk patients, TAVR was found to be superior in short-term all-cause mortality and 1-year stroke, a result that was statistically significant for TAVR and close to significance for stroke. TAVR patients were also less likely to have post-operative bleeding and AKI stage 2 and beyond. Post-operative incidence of endocarditis among TAVR patients was low but not statistically significant. However, the rates of PPM and vascular complications are higher in TAVR patients.
The results of TAVR in low risk population are thus extremely encouraging. However, the issue of long-term valve durability in this group needs further studies. Also, caution needs to be exercised while extending the indications to extremely young patients due to lack of enough studies.

\section{Acknowledgments}

Special thanks to all our team and family members whose prayers and love made it possible.

\section{Financial Disclosure}

The authors declare that no funding was required.

\section{Conflict of Interest}

The authors have no conflict of interest to declare.

\section{Informed Consent}

Written and informed consent was taken from all patients to publish their case (including publication of images).

\section{Author Contributions}

Muhammad Khan contributed to concept and design of the manuscript including the acquisition, analysis and interpretation of data as primary and corresponding author. MK also revised the work critically including the final version and agreed to be accountable for all aspects of the work. Tanveer Mir had substantial contributions to the conception or design of the work, provided the majority of images and drafted the work critically including the final version and agreed to be accountable for all aspects of the work. Waqas Ullah contributed to the analysis of cases including drafting the work for important intellectual content and final approval and agreed to be accountable for all aspects of the work. Zain Ali had substantial contributions to the conception or design of the work, provided the majority of images and drafted the work critically including the final version and agreed to be accountable for all aspects of the work. Owais Idris had significant contribution to the concept, the acquisition, analysis and interpretation of data for the work, drafted the work including the images and revised the final version of the manuscript to be published and agreed to be accountable for all aspects of the work. Ghazal Khan had substantial contributions to the conception or design of the work, provided the majority of images and drafted the work critically including the final version and agreed to be accountable for all aspects of the work. Mamoon Ur Rashid had substantial contributions to the conception or design of the work, provided the majority of images and drafted the work critically including the final version and agreed to be accountable for all aspects 
of the work. FNU Salman contributed to the analysis of cases including drafting the work for important intellectual content and final approval and agreed to be accountable for all aspects of the work. Mobasser Mehmood contributed to the analysis of cases including drafting the work for important intellectual content and final approval and agreed to be accountable for all aspects of the work. Syed Sohail Ali had significant contribution to the concept, the acquisition, analysis and interpretation of data for the work, drafted the work including the images and revised the final version of the manuscript to be published and agreed to be accountable for all aspects of the work.

\section{Data Availability}

The authors declare that data supporting the findings of this study are available within the article.

\section{References}

1. Leon MB, Smith CR, Mack MJ, Makkar RR, Svensson LG, Kodali SK, Thourani VH, et al. Transcatheter or surgical aortic-valve replacement in intermediate-risk patients. N Engl J Med. 2016;374(17):1609-1620.

2. Fraccaro C, Tarantini G, Rosato S, Tellaroli P, D'Errigo P, Tamburino C, Onorati F, et al. Early and midterm outcome of propensity-matched intermediate-risk patients aged $>/=80$ years with aortic stenosis undergoing surgical or transcatheter aortic valve replacement (from the Italian Multicenter OBSERVANT Study). Am J Cardiol. 2016;117(9):1494-1501.

3. Mack MJ, Leon MB, Thourani VH, Makkar R, Kodali SK, Russo M, Kapadia SR, et al. Transcatheter aorticvalve replacement with a balloon-expandable valve in low-risk patients. N Engl J Med. 2019;380(18):16951705.

4. Popma JJ, Deeb GM, Yakubov SJ, Mumtaz M, Gada H, O'Hair D, Bajwa T, et al. Transcatheter aortic-valve replacement with a self-expanding valve in low-risk patients. N Engl J Med. 2019;380(18):1706-1715.

5. Arora S, Strassle PD, Ramm CJ, Rhodes JA, Vaidya SR, Caranasos TG, Vavalle JP. Transcatheter versus surgical aortic valve replacement in patients with lower surgical risk scores: a systematic review and meta-analysis of early outcomes. Heart Lung Circ. 2017;26(8):840-845.

6. Nashef SA, Roques F, Michel P, Gauducheau E, Lemeshow S, Salamon R. European system for cardiac operative risk evaluation (EuroSCORE). Eur J Cardiothorac Surg. 1999;16(1):9-13.

7. Moher D, Liberati A, Tetzlaff J, Altman DG, the PRISMA Group. Reprint - preferred reporting items for systematic reviews and meta-analyses: the PRISMA statement. Phys Ther. 2009;89(9):873-880.

8. Thourani VH, Suri RM, Gunter RL, Sheng S, O'Brien SM, Ailawadi G, Szeto WY, et al. Contemporary realworld outcomes of surgical aortic valve replacement in 141,905 low-risk, intermediate-risk, and high-risk patients. Ann Thorac Surg. 2015;99(1):55-61.
9. O'Brien SM, Shahian DM, Filardo G, Ferraris VA, Haan CK, Rich JB, Normand SL, et al. The Society of Thoracic Surgeons 2008 cardiac surgery risk models: part 2 - isolated valve surgery. Ann Thorac Surg. 2009;88(1 Suppl):S23-42.

10. Shahian DM, O'Brien SM, Filardo G, Ferraris VA, Haan CK, Rich JB, Normand SL, et al. The Society of Thoracic Surgeons 2008 cardiac surgery risk models: part 3 - valve plus coronary artery bypass grafting surgery. Ann Thorac Surg. 2009;88(1 Suppl):S43-62.

11. Shahian DM, Jacobs JP, Badhwar V, Kurlansky PA, Furnary AP, Cleveland JC, Jr., Lobdell KW, et al. The society of thoracic surgeons 2018 adult cardiac surgery risk models: part 1-background, design considerations, and model development. Ann Thorac Surg. 2018;105(5):1411-1418.

12. Thyregod HG, Steinbruchel DA, Ihlemann N, Nissen $\mathrm{H}$, Kjeldsen BJ, Petursson P, Chang Y, et al. Transcatheter versus surgical aortic valve replacement in patients with severe aortic valve stenosis: 1-year results from the all-comers NOTION randomized clinical trial. J Am Coll Cardiol. 2015;65(20):2184-2194.

13. Schymik G, Heimeshoff M, Bramlage P, Herbinger T, Wurth A, Pilz L, Schymik JS, et al. A comparison of transcatheter aortic valve implantation and surgical aortic valve replacement in 1,141 patients with severe symptomatic aortic stenosis and less than high risk. Catheterization and Cardiovascular Interventions. 2015;86(4):738744.

14. Rosato S, Santini F, Barbanti M, Biancari F, D'Errigo $\mathrm{P}$, Onorati F, Tamburino C, et al. Transcatheter aortic valve implantation compared with surgical aortic valve replacement in low-risk patients. Circ Cardiovasc Interv. 2016;9(5):e003326.

15. Serruys PW, Modolo R, Reardon M, Miyazaki Y, Windecker S, Popma J, Chang Y, et al. One-year outcomes of patients with severe aortic stenosis and an STS PROM of less than three percent in the SURTAVI trial. EuroIntervention. 2018;14(8):877-883.

16. Verhagen AP, de Vet HC, de Bie RA, Kessels AG, Boers M, Bouter LM, Knipschild PG. The Delphi list: a criteria list for quality assessment of randomized clinical trials for conducting systematic reviews developed by Delphi consensus. J Clin Epidemiol. 1998;51(12):1235-1241.

17. Sondergaard L, Ihlemann N, Capodanno D, Jorgensen TH, Nissen H, Kjeldsen BJ, Chang Y, et al. Durability of transcatheter and surgical bioprosthetic aortic valves in patients at lower surgical risk. J Am Coll Cardiol. 2019;73(5):546-553.

18. Zhou Y, Wang Y, Wu Y, Zhu J. Transcatheter versus surgical aortic valve replacement in low to intermediate risk patients: A meta-analysis of randomized and observational studies. Int J Cardiol. 2017;228:723-728.

19. Gleason TG, Reardon MJ, Popma JJ, Deeb GM, Yakubov SJ, Lee JS, Kleiman NS, et al. 5-Year outcomes of selfexpanding transcatheter versus surgical aortic valve replacement in high-risk patients. J Am Coll Cardiol. 2018;72(22):2687-2696.

20. Adams DH, Popma JJ, Reardon MJ, Yakubov SJ, Coselli 
JS, Deeb GM, Gleason TG, et al. Transcatheter aorticvalve replacement with a self-expanding prosthesis. N Engl J Med. 2014;370(19):1790-1798.

21. Hamdan A, Guetta V, Klempfner R, Konen E, Raanani E, Glikson M, Goitein O, et al. Inverse relationship between membranous septal length and the risk of atrioventricular block in patients undergoing transcatheter aortic valve implantation. JACC Cardiovasc Interv. 2015;8(9):12181228.

22. Leon MB, Smith CR, Mack M, Miller DC, Moses JW, Svensson LG, Tuzcu EM, et al. Transcatheter aortic-valve implantation for aortic stenosis in patients who cannot undergo surgery. N Engl J Med. 2010;363(17):1597-1607.

23. Popma JJ, Adams DH, Reardon MJ, Yakubov SJ, Kleiman
NS, Heimansohn D, Hermiller J, Jr., et al. Transcatheter aortic valve replacement using a self-expanding bioprosthesis in patients with severe aortic stenosis at extreme risk for surgery. J Am Coll Cardiol. 2014;63(19):19721981.

24. Reardon MJ, Van Mieghem NM, Popma JJ, Kleiman NS, Sondergaard L, Mumtaz M, Adams DH, et al. Surgical or Transcatheter Aortic-Valve Replacement in IntermediateRisk Patients. N Engl J Med. 2017;376(14):1321-1331.

25. Siemieniuk RA, Agoritsas T, Manja V, Devji T, Chang Y, Bala MM, Thabane L, et al. Transcatheter versus surgical aortic valve replacement in patients with severe aortic stenosis at low and intermediate risk: systematic review and meta-analysis. BMJ. 2016;354:i5130. 